\title{
Protective host defense against disseminated candidiasis is impaired in mice expressing human interleukin-37
}

\author{
Frank L. van de Veerdonk ${ }^{1,2,3}$ *, Mark S. Gresnigt ${ }^{2}$, Marije Oosting ${ }^{2}$, Jos W. M. van der Meer ${ }^{2}$, \\ Leo A. B. Joosten ${ }^{2,3}$, Mihai G. Netea ${ }^{2,3}$ and Charles A. Dinarello ${ }^{1,2}$ \\ ${ }^{1}$ Department of Medicine, University of Colorado Denver, Denver, CO, USA \\ 2 Department of Medicine, Radboud University Nijmegen Medical Center, Nijmegen, Netherlands \\ ${ }^{3}$ Radboud Center for Infection, Nijmegen, Netherlands
}

Edited by:

Annelies Sophie Zinkernagel, University Hospital Zurich-University of Zurich, Switzerland

Reviewed by:

Thomas Tsaganos, University of Athens Medical School, Greece Stylianos Orfanos, University of Athens Medical School, Greece

\section{*Correspondence:}

Frank L. van de Veerdonk, Department of Medicine, Radboud University

Nijmegen Medical Center, Geert

Grooteplein Zuid 8, 6525 GA

Nijmegen, Netherlands

e-mail:f.veerdonk@aig.umcn.nl
The effect of the anti-inflammatory cytokine interleukin-37 (IL-37) on host defense against Candida infections remains unknown. We assessed the role of IL-37 in a murine model of disseminated candidiasis using mice transgenic for human IL-37 (hIL-37Tg). Upon exposure to Candida albicans pseudohyphae, macrophages from hIL-37Tg mice release $39 \%$ less TNF $\alpha$ compared to cells from wild-type (WT) mice $(p=0.01)$. In vivo, hIL-37Tg mice displayed a decreased capacity to recruit neutrophils to the site of infection. These defects were associated with increased mortality and organ fungal growth in hIL-37Tg compared to WT mice. We conclude that IL-37 interferes with the innate protective antiCandida host response by reducing the production of proinflammatory cytokines and suppressing neutrophil recruitment in response to Candida, resulting in an increased susceptibility to disseminated candidiasis.

Keywords: IL-37, Candida, TNF $\alpha$, inflammation, neutrophils, antifungal host defense, IL-1F7

\section{INTRODUCTION}

The interleukin-1 (IL-1) family includes inflammatory cytokines (such as IL-1 $\alpha$, IL-1 $\beta$, IL-18, and IL-33) that activate target cells through a receptor-mediated mechanism; anti-inflammatory cytokine antagonists (such as IL-1Ra) block IL-1-dependent activation by competing for binding to the IL-1 receptors (Dinarello, 2011). Twelve years ago, using in silico searches, additional members of the IL-1 family namely IL-36, IL-37, and IL-38 were discovered, but only recently have their properties been studied (Dinarello, 2013). In the case of IL-37, this cytokine has emerged as fundamental inhibitor of innate inflammation using mice transgenic for human IL-37 as well as reducing endogenous IL-37 in human blood monocytes (Nold et al., 2010). For example, mice transgenic for human IL-37 are protected against systemic endotoxemia, chemical induced colitis, ConA hepatitis, and ischemic reperfusion injury, as reviewed in Dinarello and Bufler (2013). The mechanism by which IL-37 affords anti-inflammatory protection can be via a caspase-1-dependent nuclear translocation or by an extracellular mechanism engaging the IL-18 receptor (Bulau et al., 2014). It is important however, to recognize that antiinflammatory strategies based upon IL-37 could have a negative impact on susceptibility to infections by inhibiting host defense. Since in models of live infection blocking inflammation mediated by cytokines such as IL-1 or TNF $\alpha$ can be either detrimental or beneficial for the outcome of the host, we therefore carried-out studies of disseminated candidiasis in mice expressing human IL-37.

\section{MATERIALS AND METHODS ANIMALS}

Transgenic mice expressing human IL-37 (hIL-37Tg) have been previously described Nold et al. (2010). Control C57BL/6J (WT) mice were purchased from the Jackson Laboratory and maintained under specific-pathogen free conditions. The mice were fed sterilized laboratory chow (Hope Farms, Woerden, The Netherlands) and water ad libitum. The experiments were approved by the Ethics Committee on Animal Experiments of Radboud University Nijmegen.

\section{Candida albicans AND GROWTH CONDITIONS}

Candida albicans ATCC MYA-3573 (UC 820), a strain well described elsewhere (Lehrer and Cline, 1969), was used in all experiments. Candida was grown overnight in Sabouraud broth at $37^{\circ} \mathrm{C}$, cells were harvested by centrifugation, washed twice, and resuspended in culture medium (RPMI-1640 Dutch modification, ICN Biomedicals, Aurora, OH, USA; van der Graaf et al., 2005). To generate pseudohyphae, C. albicans blastoconidia were grown at $37^{\circ} \mathrm{C}$ in culture medium, adjusted to $\mathrm{pH} 6.4$ by using hydrochloric acid. Pseudohyphae were killed at $100^{\circ} \mathrm{C}$ for $1 \mathrm{~h}$ and resuspended in culture medium to a hyphal inoculum size that originated from $10^{6}$ blastoconidia per $\mathrm{ml}$ (referred to as $10^{6}$ pseudohyphae per $\mathrm{ml}$ ).

\section{CYTOKINE RESPONSES OF $\boldsymbol{C}$. albicans-STIMULATED MACROPHAGES AND SPLENOCYTES}

Resident peritoneal macrophages were harvested from groups of five hIL-37Tg and wild-type (WT) mice by injecting $4 \mathrm{ml}$ of sterile phosphate-buffered saline (PBS) intrapertitoneal containing $0.38 \%$ sodium citrate (Kullberg et al., 1993). After washing, the cells were resuspended in culture medium in 96-well microtiter plates (Greiner, Alphen, The Netherlands) at $10^{5}$ cells/well, in a final volume of $200 \mu$ l. The cells were stimulated with either control medium or heat killed C. albicans at $1 \times 10^{7}$ microorganisms $/ \mathrm{ml}$. After $24 \mathrm{~h}$ of incubation at $37^{\circ} \mathrm{C}$, 
the plates were centrifuged (500 g, $10 \mathrm{~min}$ ), and the supernatants were removed. The cells were lysed with three freeze-thaw cycles. Samples were stored at $-80^{\circ} \mathrm{C}$ until cytokine assays were performed.

To assess cytokine production in splenocytes, spleen were gently squeezed into a sterile $200 \mathrm{~mm}$ filter chamber. The cells were washed and resuspended in RPMI 1640, counted in a Bürker chamber and adjusted to $5 \times 10^{6} / \mathrm{ml} .200 \mu \mathrm{L}$ of the cell suspension was stimulated with $1 \times 10^{7}$ heat-killed C. albicans $/ \mathrm{ml}$. Measurement of TNF $\alpha$ and IL- 6 concentrations was performed in supernatants collected after $48 \mathrm{~h}$ of incubation at $37^{\circ} \mathrm{C}$ in $5 \% \mathrm{CO}_{2}$ in 48-well plate.

\section{CYTOKINE ASSAYS}

$\mathrm{TNF} \alpha$ was determined by specific radioimmunoassay (detection limit $20 \mathrm{pg} / \mathrm{ml}$ ), as previously described Netea et al. (1996). IL-6 concentrations were determined by a commercial ELISA (Biosource, Camarillo, CA, USA, detection limit 16 pg/ml) according to the instructions of the manufacturer.

\section{C. albicans INFECTION MODEL}

hIL-37Tg mice and WT mice were injected intravenously with C. albicans blastoconidia $\left(1 \times 10^{6} \mathrm{CFU} / \mathrm{mouse}\right.$ for survival and $5 \times 10^{5} \mathrm{CFU} /$ mouse for testing fungal burden) in a $100 \mu \mathrm{l}$ volume of sterile pyrogen-free PBS. Survival was assessed daily for 2 weeks. Subgroups of five animals were killed on days 3 and 7 of infection. To assess the tissue outgrowth of the microorganisms, the kidneys of the sacrificed animals were removed aseptically, weighed, and homogenized in sterile saline in a tissue grinder. The number of viable Candida cells in the tissues was determined by plating serial dilutions on Sabouraud dextrose agar plates. The CFU were counted after $24 \mathrm{~h}$ of incubation at $37^{\circ} \mathrm{C}$, and expressed as $\log$ $\mathrm{CFU} / \mathrm{g}$ tissue.

\section{Candida OUTGROWTH IN PMN DEPLETED MICE}

Sexually mature female C57bl/6 mice (8-12 weeks old, weights 20$25 \mathrm{~g})$ were used. The animals were kept under routine laboratory conditions $\left(21-22^{\circ} \mathrm{C}\right.$, relative humidity $60 \%$ and a $12 \mathrm{~h}$ light-dark cycle), fed a standard commercial pellet diet (RHM, Hope Farms, The Netherlands), and given acidified tap water ad libitum. The mice were injected intraperitoneal with rat anti-mouse GR1 or isotype control (100 $\mu \mathrm{g}$ in $200 \mu \mathrm{l} \mathrm{PBS}$; eBioscience) 4 days prior to the experiment to deplete the mice of PMNs. On day zero, the mice were injected intraperitoneal with $1 \times 10 \mathrm{e} 5$ live C. albicans conidia. After $2 \mathrm{~h}$ the mice were anesthetized with isoflurane and blood samples were obtained for measurement of blood cells counts. Subsequently, the mice were sacrificed by cervical dislocation. The number of viable Candida cells in the peritoneal lavage was determined by plating serial dilutions on Sabouraud dextrose agar plates and the CFU were counted after $24 \mathrm{~h}$ of incubation at $37^{\circ} \mathrm{C}$ and expressed as $\log \mathrm{CFU}$.

\section{IN VITRO CYTOKINE PRODUCTION BY PRIMED SPLENOCYTES}

To assess cytokine production during infection, primed spleen cells from mice on day 7 of infection with $2 \times 10^{5} \mathrm{CFU}$ of C. albicans per mouse were stimulated in vitro with heat-killed Candida conidia or pseudohyphae $\left(1 \times 10^{6}\right.$ microorganisms $\left./ \mathrm{ml}\right)$. Spleen cells were washed and resuspended in RPMI1640, counted in a Bürker chamber and the number was adjusted to $5 \times 10^{6} / \mathrm{ml}$. $200 \mu \mathrm{L}$ of the cell suspension was stimulated with $1 \times 10^{6}$ heat killed C. albicans/ml. Measurement of IFN $\gamma$, IL-10, and IL-17 concentrations was performed in supernatants collected after $48 \mathrm{~h}$ of incubation at $37^{\circ} \mathrm{C}$ in $5 \% \mathrm{CO}_{2}$ in 48 -well plate.

\section{PHAGOCYTOSIS AND KILLING OF C. albicans BY MACROPHAGES}

Phagocytosis and killing of $C$. albicans blastoconidia were assessed as described elsewhere (Vonk et al., 2006). Exudate peritoneal phagocytes from groups of five hIL-37Tg mice and WT mice were elicited by an i.p. injection of $10 \%$ proteose peptone. After $72 \mathrm{~h}$, cells were collected in separate sterile tubes by washing the peritoneal cavity with $4 \mathrm{ml}$ of ice-cold PBS that contained $50 \mathrm{U} / \mathrm{ml}$ heparin. Phagocytes were centrifuged (for $10 \mathrm{~min}$ at $2250 \mathrm{~g}$ ), counted in a Bürker chamber, and resuspended in culture medium. $5 \times 10^{5}$ cells were dispensed into the wells of a 96-well flat bottom plate (Costar), allowed to adhere for $2 \mathrm{~h}$, and washed to remove non-adherent cells. Subsequently, the cells were incubated with $1 \times 10^{4} \mathrm{CFU}$ C. albicans, which were opsonized for $45 \mathrm{~min}$ at $24^{\circ} \mathrm{C}$ in modified Eagle's medium (MEM; Gibco Life Technologies) containing 2.5\% fresh mouse serum (effector:target ratio, 40:1). After $15 \mathrm{~min}$, supernatants were aspirated, and monolayers were gently washed with MEM to remove non-ingested microorganisms. The supernatant and well washings that contained the noningested Candida blastoconidia were plated in serial dilutions on Sabouraud agar plates. The percentage of phagocytosed microorganisms was defined as [1-(number of uningested CFU/CFU at the start of incubation) $] \times 100$. Killing of C. albicans by phagocytes was assessed in the same monolayers. After removal of the nonphagocytized Candida blastoconidia, 200 $\mu$ l of culture medium, consisting of Sabouraud in MEM (50\% vol/vol), was added to the monolayers. After $3 \mathrm{~h}$ of incubation at $37^{\circ} \mathrm{C}$ in air and $5 \%$ $\mathrm{CO}_{2}$, the wells were scraped gently with a plastic paddle and washed with $200 \mu \mathrm{l}$ distilled $\mathrm{H}_{2} \mathrm{O}$ to achieve lysis of phagocytes in three cycles, and 10-fold dilutions of each sample were spread on Sabouraud agar plates and incubated at $37^{\circ} \mathrm{C}$ for $24 \mathrm{~h}$. The percentage of yeast killed by the phagocytes was determined as follows: [1-(CFU after incubation/number of phagocytized CFU)] (Nold et al., 2010) × 100. Phagocyte-free incubations of blastoconidia were included as a control for yeast viability. In earlier experiments we have shown that 90-97\% of attached/internalized C. albicans are intracellular (Vonk et al., 2006).

\section{STATISTICAL ANALYSIS}

The differences between groups were analyzed by the MannWhitney $U$-test. The level of significance between groups was set at $p<0.05$. The data are presented as cumulative results of all experiments performed.

\section{RESULTS}

hIL-37Tg MICE ARE MORE SUSCEPTIBLE TO DISSEMINATED C. albicans INFECTION

To investigate the role of IL-37 in the host defense against invasive C. albicans infection, hIL-37Tg mice, and WT mice were infected with C. albicans blastospores. The survival during disseminated candidiasis was $20 \%$ for WT-type mice after 2 weeks, whereas all 
mice had died by day 10 in the hIL-37Tg group (Figure 1A). The fungal burden in the kidneys, the target organ of disseminated candidiasis in mice (Spellberg et al., 2005), was not significantly different at day 3 (mean \pm SD; WT: $3.6 \pm 0.83$, IL-37Tg $3.8 \pm$ $0.44 \log \mathrm{CFU} / \mathrm{g}$ kidney), and 1-log higher in the hIL-37Tg mice than in WT mice on day 7 of infection $(p<0.05$; Figure 1B). Histology revealed an accumulation of Candida in the pyelum of the kidneys of hIL-37Tg mice which was not observed in the WT mice (Figure 1C).

\section{NEUTROPHIL RECRUITMENT AND PHAGOCYTOSIS AND KILLING OF C. albicans}

In order to understand the enhanced lethality and greater fungal burden of the hIL-37Tg mice, we investigated the dynamics of the influx and function of neutrophils. Peritoneal cells were harvested and counted $4 \mathrm{~h}$ after intraperitoneal injection of heat-killed Candida. A significant lower influx of neutrophils was apparent $4 \mathrm{~h}$ after challenge with heat killed Candida in the hIL37Tg mice compared to WT mice (Figure 2A). Phagocytosis of C. albicans by hIL-37Tg cells was similar to that by cells of WT mice (37 vs. $39 \%$ phagocytized in $15 \mathrm{~min} ; p>0.05$ ). hIL-37Tg cells killed $92 \%$ of phagocytized Candida blastoconidia after $3 \mathrm{~h}$, which was not different from the killing activity of cells from WT cells $(88 \%$, $p>0.05$, Figure 2B).

To assess whether the decrease of neutrophils within the first hours has a significant biological effect, we investigated the difference of fungal burden between neutrophil depleted mice and non-neutrophil depleted mice in a short in vivo Candida infection model. The lack of neutrophils at the site of infection resulted in a log increase in fungal growth within $2 \mathrm{~h}$ compared to mice in which neutrophil influx was normal (Figure 2C). These differences support the importance of early influx of neutrophils in restricting Candida growth in vivo.

\section{IL-37 INHIBITS PROINFLAMMATORY CYTOKINE PRODUCTION BY MACROPHAGES AND SPLENOCYTES STIMULATED WITH C. albicans}

To investigate the inhibitory effect of IL-37 at the level of cytokine production, resident peritoneal macrophages, or naïve splenocytes of hIL-37Tg and WT mice were exposed to heat-killed C. albicans blastoconidia and pseudohyphae in vitro. Cytokine production by unstimulated macrophages of each mouse strain was below the detection limit for TNF $\alpha$ and IL-6. However, after stimulation with C. albicans pseudohyphae, the production of TNF $\alpha$ was significantly lower in macrophages from the hIL-37Tg mice compared to cells from WT mice. There were no differences in the production of IL-6 in the same cultures (Figure 3).

\section{hIL-37Tg MICE DISPLAY INCREASED Th17 AND IL-10 RESP0NSES}

Proinflammatory $\mathrm{T}$ helper responses such as Th1 and Th17 responses play an important role in fungal host defense (Gow et al., 2012). The Th17 response during disseminated fungal infection can be both protective and detrimental (Huang et al., 2004; Zelante et al., 2007; Lin et al., 2009). To study the impact of IL-37 on proinflammatory adaptive immune responses, we investigated the Th1 and Th17 characteristic cytokines IFN $\gamma$ and IL-17. Splenocytes isolated from hIL-37Tg mice with a higher fungal burden at day 7 produced significant more IL-17 in response to $C$. albicans pseudohyphae (Figure 4). IFN $\gamma$ production in response to $C$. albicans pseudohyphae was undetectable in WT and hIL-37Tg splenocytes at day 7 (Figure 4). Since IL-37 mainly has anti-inflammatory effects (Nold et al., 2010; Boraschi et al., 2011), we investigated levels of IL-10 in cells from IL-37Tg There was no significant difference in IL-10 production in splenocytes from hIL-37Tg compared to WT cells in response to C. albicans, although hIL-37Tg mice showed a trend toward an increased IL-10 production (Figure 4).

\section{DISCUSSION}

In the present study, we demonstrate that overexpression of IL37 is detrimental for the early host defense against C. albicans in a murine model of disseminated candidiasis. This conclusion is based on the increased fungal load in the kidney, the target organ of disseminated candidiasis, in hIL-37Tg mice compared to WT mice. The greater outgrowth of the fungus in the tissues is most probably due to impaired early influx of neutrophils into the infected tissues, which in turn may be due to lower production of neutrophil-inducing cytokines, such as TNF. Therefore, the

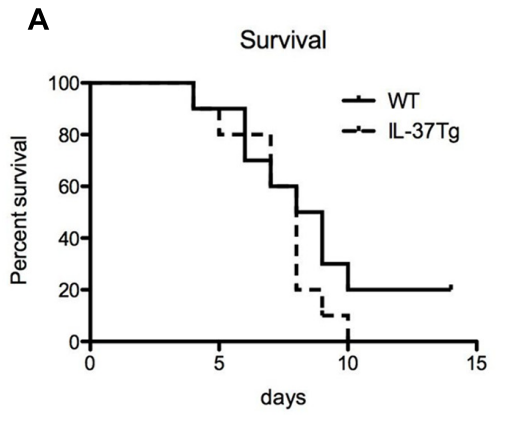

FIGURE 1 | hIL-37Tg mice are highly susceptible to disseminated C. albicans infection. (A) Survival of hIL-37Tg mice and WT mice intravenously infected with live C. albicans yeast $(1 \times 10$ e 6 CFU). (B) hIL-37Tg mice and WT mice were infected i.v. with C. albicans blastoconidia ( $5 \times 10$ e5 CFU/mouse). Subgroups of animals (a total of nine mice/group/time point, in two separate experiments) were killed on
B

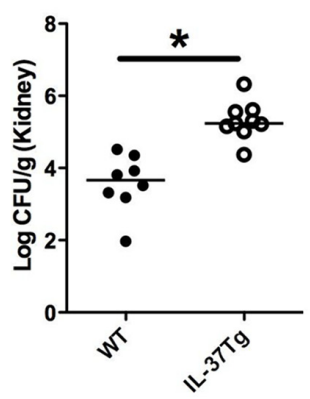

C

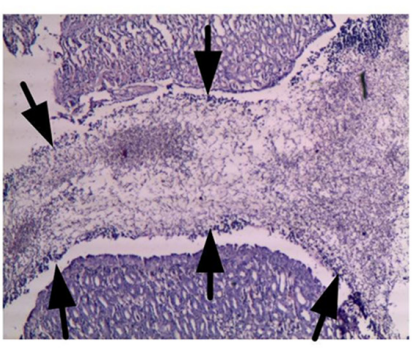

day 7 of infection, and fungal outgrowth was assessed in the kidneys. (C) Histology representing the accumulation of $C$. albicans hyphae (fungal ball) in the pyelum of hIL-37Tg mice. Arrows point to the edge of the fungal ball present in the pyelum of the kidney (A). Survival was assessed daily for 2 weeks. ( $n=10 /$ group; B) Mann-Whitney $U$-test, ${ }^{*} p<0.05$. 

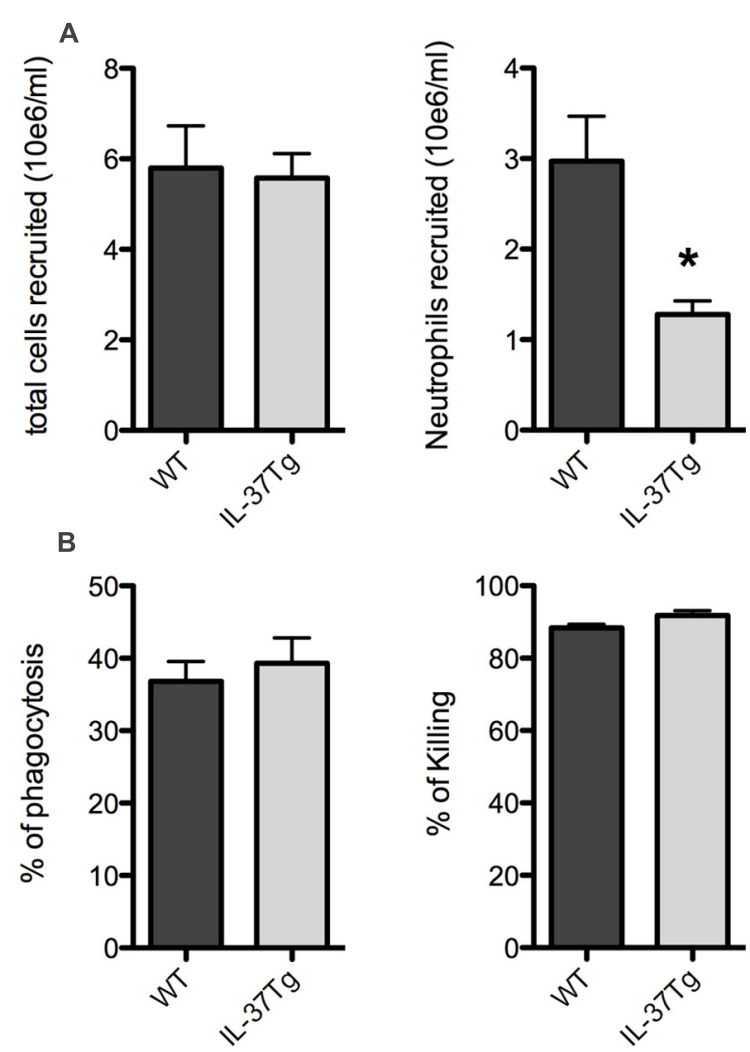

C

Peritoneal wash out $2 \mathrm{~h}$ post infection

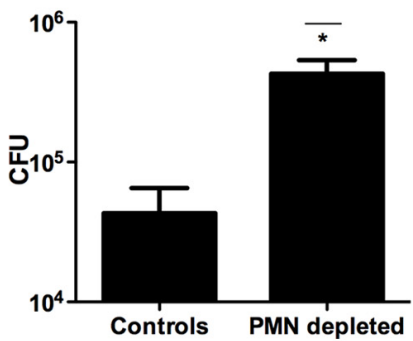

FIGURE 2 | Neutrophil recruitment and phagocytosis and killing of $\boldsymbol{C}$. albicans. (A) Absolute numbers of total cells and absolute numbers of neutrophils recruited to the peritoneal cavity of WT and hIL-37Tg mice $4 \mathrm{~h}$ after intraperitoneal injection of $1 \times 10 \mathrm{e} 7$ heat killed $C$. albicans yeasts. (B) Percentage of Candida blastoconidia of the initial inoculum that was ingested by macrophages of hIL-37Tg and WT mice after 15 min of phagocytosis and percentage of phagocytized Candida blastoconidia that was killed after incubation at $37^{\circ} \mathrm{C}$ for $3 \mathrm{~h}$ is shown. The results are pooled data with a total of five hlL-37Tg mice and five WT mice (mean \pm SEM, ${ }^{*} p<0.05$, Students $t$-test). (C) Fungal outgrowth of peritoneal wash-outs in neutrophil (PMN) depleted and non-PMN depleted WT mice $2 \mathrm{~h}$ after intraperitoneal infection with live Candida. The results are pooled data with a total of four hIL-37Tg mice and four WT mice (mean \pm SEM, ${ }^{*} p<0.05$, Students $t$-test)

presence of IL-37 in the early stages of infection results in an impaired innate immune response that is essential to limit fungal dissemination.

Recently, several biological functions of the cytokine IL-37 have been described. IL-37 has a protective role in a murine model

\section{Peritoneal macrophages}

C. albicans blastoconidia

C. albicans pseudohyphae
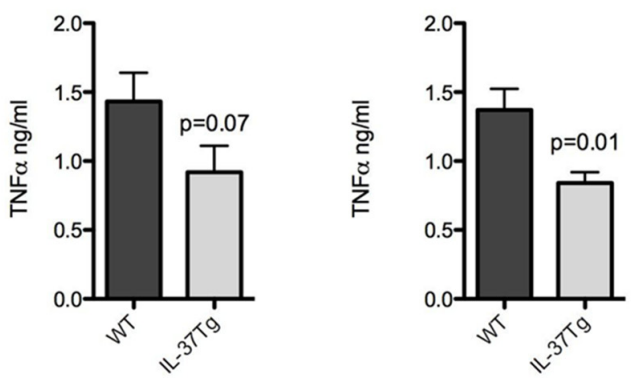

C. albicans blastoconidia

C. albicans pseudohyphae
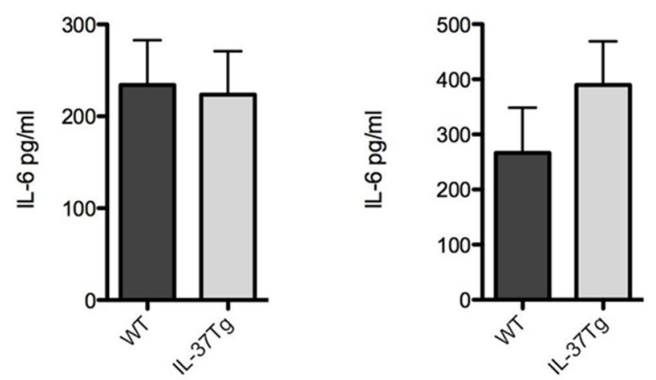

\section{Splenocytes}

C. albicans blastoconidia

C. albicans blastoconidia
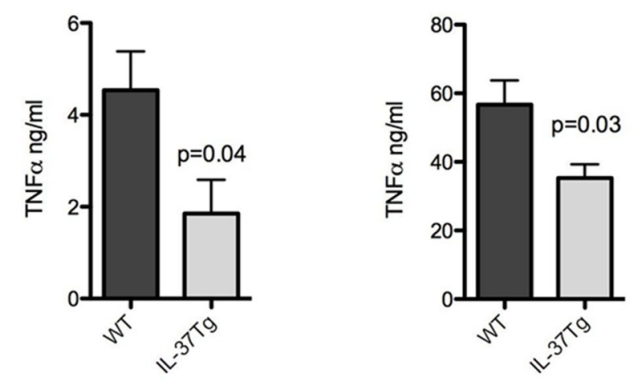

FIGURE 3 | IL-37 inhibits proinflammatory cytokine production by macrophages and splenocytes stimulated with $C$. albicans. (A)

Resident peritoneal macrophages from hIL-37Tg mice and WT mice were stimulated with either $1 \times 10$ e7 microorganisms $/ \mathrm{ml}$ heat-killed Candida blastoconidia or pseudohyphae. (B) Splenocytes from hIL-37Tg mice and WT mice were stimulated with either $1 \times 10 \mathrm{e} 7$ microorganisms $/ \mathrm{ml}$ Candida blastoconidia or pseudohyphae. Production of TNF $\alpha$ and IL-6 in the supernatants was measured after $24 \mathrm{~h}$ of stimulation at $37^{\circ} \mathrm{C}$ for macrophages and $48 \mathrm{~h}$ of stimulation at $37^{\circ} \mathrm{C}$ for splenocytes. The results are pooled data with a total of seven hIL-37Tg mice and six WT mice (mean \pm SEM, * $p<0.05$, Mann-Whitney $U$-test). 


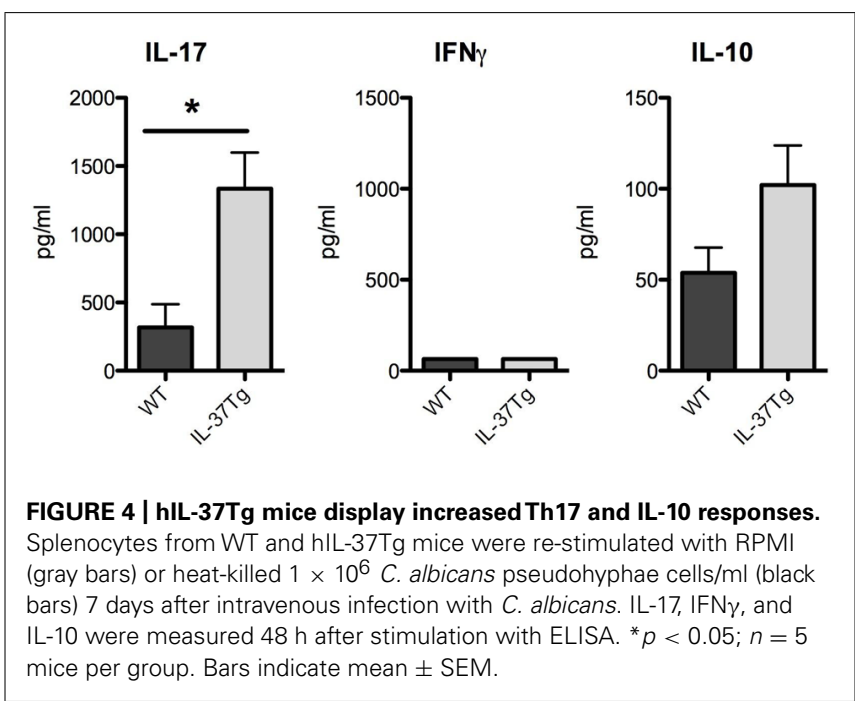

model, the murine model of disseminated candidiasis, in which we assessed whether IL-37 hampers the innate immune defense against a fungal infection. We observed that mice overexpressing IL-37 were more susceptible to invasive candidiasis, due to the inability to control fungal growth in the kidney during infection. This effect is at least partly due to a defective neutrophil recruitment, a cell population central for the local antifungal host defense (Kullberg et al., 1990), and this supports the previously reported finding that leukocyte recruitment to the site of inflammation is decreased in hIL-37Tg mice (McNamee et al., 2011). The importance of neutrophils in the control of Candida outgrowth in vivo is further supported in this study by the observation that neutrophil depleted mice have a log increase within $2 \mathrm{~h}$ in fungal burden compared to mice that have a normal neutrophil influx. In addition, macrophages and splenocytes overexpressing IL-37 produced significantly less $\mathrm{TNF} \alpha$ than WT macrophages when exposed to C. albicans. This is in line with other studies, showing that macrophages from hIL-37Tg mice produce less TNF and that IL-37 overexpression reduces TNF-dependent inflammation in a murine model of colitis (McNamee et al., 2011). An involvement of defective TNF production in the increased susceptibility of hIL-37Tg mice to disseminated candidiasis is also consistent with earlier studies showing that mice lacking TNF or the TNF receptor are highly susceptible to disseminated candidiasis (Netea et al., 1999).

Another observation of this study is that neutrophils from hIL-37Tg mice do not display an intrinsic defect in phagocytosis and killing, suggesting that IL-37 does not directly impair neutrophil function. The increased Th17 response in hIL-37Tg mice present on day 7 most likely reflects an increased cellular immune response due to higher fungal burden (antigen) exposure. Whether this increased Th17 response has directly contributed to the higher susceptibility of hIL-37Tg mice to disseminated candidiasis remains to be determined. Interestingly, hIL-37Tg splenocytes showed a consistent trend at day 7 toward an increased production of the anti-inflammatory cytokine IL10 when exposed to $C$. albicans. This observation is consistent with the increased IL-10 production found in hIL-37Tg mice with experimental colitis, and supports the concept that IL-37 can contribute to systemic anti-inflammatory effects (McNamee et al., 2011).

In conclusion, IL-37 reduces proinflammatory cytokine production induced by Candida in macrophages, and decreases neutrophil recruitment in vivo in response to $C$. albicans. These data highlight the potent anti-inflammatory effects of IL-37, and underline that the timing of IL-37 expression in the tissue at the site of inflammation is critical for the outcome of the host during inflammatory processes.

\section{ACKNOWLEDGMENTS}

This study was supported by the Niels Stensen Foundation and a Veni Grant of the Netherlands Foundation for Scientific Research to Frank L. van de Veerdonk. Charles A. Dinarello was supported by NIH grant AI-15614.

\section{REFERENCES}

Boraschi, D., Lucchesi, D., Hainzl, S., Leitner, M., Maier, E., Mangelberger, D., et al. (2011). IL-37: a new anti-inflammatory cytokine of the IL-1 family. Eur. Cytokine Netw. 22, 127-147. doi: 10.1684/ecn.2011.0288

Bulau, A. M., Fink, M., Maucksch, C., Kappler, R., Mayr, D., Wagner, K., et al. (2011). In vivo expression of interleukin-37 reduces local and systemic inflammation in concanavalin a-induced hepatitis. Sci. World J. 11, 2480-2490. doi: 10.1100/2011/968479

Bulau, A. M., Nold, M. F., Li, S., Nold-Petry, C. A., Fink, M., Mansell, A., et al. (2014). Role of caspase-1 in nuclear translocation of IL-37, release of the cytokine, and IL-37 inhibition of innate immune responses. Proc. Natl. Acad. Sci. U.S.A. 111, 2650-2655. doi: 10.1073/pnas.1324140111

Dinarello, C. A. (2011). Interleukin-1 in the pathogenesis and treatment of inflammatory diseases. Blood 117, 3720-3732. doi: 10.1182/blood-2010-07273417

Dinarello, C. A. (2013). Overview of the interleukin-1 family of ligands and receptors. Semin. Immunol. 25, 389-393. doi: 10.1016/j.smim.2013. 10.001

Dinarello, C. A., and Bufler, P. (2013). Interleukin-37. Semin. Immunol. 25, 466-468. doi: 10.1016/j.smim.2013.10.004

Gow, N. A., van de Veerdonk, F. L., Brown, A. J., and Netea, M. G. (2012). Candida albicans morphogenesis and host defence: discriminating invasion from colonization. Nat. Rev. Microbiol. 10, 112-122. doi: 10.1038/nrmicro2711

Huang, W., Na, L., Fidel, P. L., and Schwarzenberger, P. (2004). Requirement of interleukin-17A for systemic anti-Candida albicans host defense in mice. J. Infect. Dis. 190, 624-631. doi: 10.1086/422329

Kullberg, B. J., van 't Wout, J. W., Hoogstraten, C., and Van Furth, R. (1993). Recombinant interferon- $\gamma$ enhances resistance to acute disseminated Candida albicans infection in mice. J. Infect. Dis. 168, 436-443. doi: 10.1093/infdis/168. 2.436

Kullberg, B. J., van 't Wout, J. W., and Van Furth, R. (1990). Role of granulocytes in enhanced host resistance to Candida albicans induced by recombinant interleukin-1. Infect. Immun. 58, 3319-3324.

Lehrer, R. I., and Cline, M. J. (1969). Interactions of Candida albicans with human leukocytes and serum. J. Bacteriol. 98, 996-1004.

Lin, L., Ibrahim, A. S., Xu, X., Farber, J. M., Avanesian, V., Baquir, B., et al. (2009). Th1-Th17 cells mediate protective adaptive immunity against Staphylococcus aureus and Candida albicans infection in mice. PLoS Pathog. 5:e1000703. doi: 10.1371/journal.ppat.1000703

McNamee, E. N., Masterson, J. C., Jedlicka, P., McManus, M., Grenz, A., Collins, C. B., et al. (2011). Interleukin 37 expression protects mice from colitis. Proc. Natl. Acad. Sci. U.S.A. 108, 16711-16716. doi: 10.1073/pnas.1111982108

Netea, M. G., Demacker, P. N. M., Kullberg, B. J., Boerman, O. C., Verschueren, I., Stalenhoef, A. F., et al. (1996). Low-density-lipoprotein receptor deficient mice are protected against lethal endotoxinemia and severe gram-negative infections. J. Clin. Invest. 97, 1366-1372. doi: 10.1172/JCI118556

Netea, M. G., Van Tits, L. J. H., Curfs, J. H. A. J., Amiot, F., Meis, J. F. G. M., van der Meer, J. W. M., et al. (1999). The increased susceptibility of TNF $\alpha$ LT $\alpha$ 
double knock-out mice to systemic candidiasis is due to defective recruitment and phagocytosis by neutrophils. J. Immunol. 163, 1498-1505.

Nold, M. F., Nold-Petry, C. A., Zepp, J. A., Palmer, B. E., Bufler, P., and Dinarello, C. A. (2010). IL-37 is a fundamental inhibitor of innate immunity. Nat. Immunol. 11, 1014-1022. doi: 10.1038/ni.1944

Spellberg, B., Ibrahim, A. S., Edwards, J. E. Jr., and Filler, S. G. (2005). Mice with disseminated candidiasis die of progressive sepsis. J. Infect. Dis. 192, 336-343. doi: $10.1086 / 430952$

van der Graaf, C. A. A., Netea, M. G., Verschueren, I., van der Meer, J. W. M., and Kullberg, B. J. (2005). Differential cytokine production and Toll-like receptor signaling pathways by Candida albicans blastoconidia and hyphae. Infect. Immun. 73, 7458-7464. doi: 10.1128/IAI.73.11.7458-7464.2005

Vonk, A. G., Netea, M. G., van Krieken, J. H., Iwakura, Y., van der Meer, J. W., and Kullberg, B. J. (2006). Endogenous interleukin (IL)-1 alpha and IL-1 beta are crucial for host defense against disseminated candidiasis. J. Infect. Dis. 193, 1419-1426. doi: 10.1086/503363

Zelante, T., De Luca, A., Bonifazi, P., Montagnoli, C., Bozza, S., Moretti, S., et al. (2007). IL-23 and the Th17 pathway promote inflammation and impair antifungal immune resistance. Eur. J. Immunol. 37, 2695-2706. doi: 10.1002/eji.200737409
Conflict of Interest Statement: The authors declare that the research was conducted in the absence of any commercial or financial relationships that could be construed as a potential conflict of interest.

Received: 28 October 2014; accepted: 15 December 2014; published online: 07 January 2015.

Citation: van de Veerdonk FL, Gresnigt MS, Oosting M, van der Meer JWM, Joosten LAB, Netea MG and Dinarello CA (2015) Protective host defense against disseminated candidiasis is impaired in mice expressing human interleukin-37. Front. Microbiol. 5:762. doi: 10.3389/fmicb.2014.00762

This article was submitted to Infectious Diseases, a section of the journal Frontiers in Microbiology.

Copyright () 2015 van de Veerdonk, Gresnigt, Oosting, van der Meer, Joosten, Netea and Dinarello. This is an open-access article distributed under the terms of the Creative Commons Attribution License (CC BY). The use, distribution or reproduction in other forums is permitted, provided the original author(s) or licensor are credited and that the original publication in this journal is cited, in accordance with accepted academic practice. No use, distribution or reproduction is permitted which does not comply with these terms. 